Article

\title{
Atmospheric Plasma Spraying of Single Phase Lanthanum Zirconate Thermal Barrier Coatings with Optimized Porosity ${ }^{\dagger}$
}

\author{
Georg Mauer*, Linnan Du and Robert Vaßen \\ Forschungszentrum Jülich GmbH, Institute of Energy and Climate Research (IEK-1); 52425 Jülich, Germany; \\ linnan.du@gmail.com (L.D.); r.vassen@fz-juelich.de (R.V.) \\ * Correspondence: g.mauer@fz-juelich.de; Tel.: +49-2461-61-5671 \\ + This article was presented as a key note lecture at the 30th International Conference on Surface Modification \\ Technologies (SMT30), held 29 June-1 July 2016, in Milan, Italy, and has been expanded from the original \\ conference proceedings.
}

Academic Editor: Alessandro Lavacchi

Received: 16 August 2016; Accepted: 14 October 2016; Published: 18 October 2016

\begin{abstract}
The shortcomings at elevated operation temperatures of the standard material yttria-stabilized zirconia (YSZ) for thermal barrier coatings (TBCs) have initiated many research activities seeking alternatives. One candidate is the pyrochlore lanthanum zirconate $\mathrm{La}_{2} \mathrm{Zr}_{2} \mathrm{O}_{7}$ (LZ), which is phase-stable to its melting point. At the same time, it shows a lower thermal conductivity and a lower sintering tendency when compared to YSZ. Because of its low thermal expansion coefficient and poor toughness, it is applied in combination with YSZ in double layer TBC systems. It is the current state of knowledge that LZ is prone to lanthanum depletion if processed by plasma spraying. The process conditions have to be selected carefully to avoid this. Furthermore, the amount and morphology of the coating porosity is essential for a good thermo-mechanical performance. In this work, the development and testing of LZ/YSZ double layer TBC systems is described. Initially, suitable basic parameters (torch, plasma gas composition, and power) were tested with respect to coating stoichiometry. Then, microstructures were optimized by adjusting feed rate, spray distance, and by selecting a more appropriate feedstock. Powder particles and coatings were characterized by digital image analysis.
\end{abstract}

Keywords: lanthanum zirconate; thermal barrier coating; microstructure; atmospheric plasma spraying

\section{Introduction}

In modern gas turbines, plasma-sprayed thermal barrier coating (TBC) systems have been applied for several decades to improve performance. The thermally insulating layer can reduce the temperature of the metallic substrate, resulting in improved component durability. Furthermore, an improvement in efficiency can be achieved by permitting an increase of the turbine inlet temperatures. Thus, TBCs offer great benefits for the operation of gas turbine aircraft engines, gas turbine shipboard engines, and land-based industrial gas turbine engines [1].

Such TBC systems are complex, multi-layered, and multi-material systems with many variants related to composition, processing, and microstructure. They consist of at least two layers-a bond coat layer and an insulating ceramic topcoat. The bond coat is often a metal, and has two major functions. It improves bonding between the substrate and the topcoat, and it protects the substrate from corrosion and oxidation. The ceramic topcoat provides heat insulation by its low thermal conductivity, resulting from bulk material characteristics as well as from microstructural features such as pores and voids [2]. 
Partially yttria stabilized zirconia (YSZ) with 6 to $8 \mathrm{wt} . \%$ yttria content is frequently used as a TBC material due to its high thermal expansion coefficient and its relatively good fracture toughness. YSZ formed by Electron Beam-Physical Vapor Deposition (EB-PVD) or Atmospheric Plasma Spraying (APS) consists of a metastable $t^{\prime}$-phase. Upon prolonged exposure at elevated temperatures, it decomposes into high-yttria and low-yttria phases. The latter transforms upon cooling into the monoclinic phase, with an associated large volume increase; this may prove to be catastrophic, resulting in failure of the $\mathrm{TBC}$ [3]. The accepted upper limit for use is $1200^{\circ} \mathrm{C}$. In addition to the limited phase stability, sintering also reduces the high-temperature capability, as it leads to a loss of strain tolerance of the coatings and hence early failure [4].

These shortcomings have initiated many research activities seeking even better ceramics than YSZ $[5,6]$. In particular, several zirconate pyrochlores show low thermal conductivities and high thermal stabilities. Among them, lanthanum zirconate $\mathrm{La}_{2} \mathrm{Zr}_{2} \mathrm{O}_{7}$ (LZ) is phase-stable to its melting point. At the same time, it displays a lower thermal conductivity $\left(1.56 \mathrm{Wm}^{-1} \mathrm{~K}^{-1}\right.$, bulk material) and a lower sintering tendency when compared to YSZ. However, the thermal expansion coefficient of $9.1 \times 10^{-6} \mathrm{~K}^{-1}\left(30-1000{ }^{\circ} \mathrm{C}\right)$ [5] is low in relation to bond coats and Ni-base alloy substrates $\left(\sim 15 \times 10^{-6} \mathrm{~K}^{-1}\right)$, and the toughness is poor [7]. For this reason, pyrochlores are applied in combination with YSZ in double-layer TBC systems [8-11]. YSZ is applied as the first ceramic layer, since TBC failure is often initiated by cracks occurring close to the bond coat. Furthermore, this YSZ interlayer can prevent possible reactions between the pyrochlore and the alumina-based scale (thermally-grown oxide, TGO) formed on the bond coat under thermal load [12].

The $\mathrm{La}_{2} \mathrm{O}_{3} \cdot \mathrm{ZrO}_{2}$ phase diagram shows a stable pyrochlore region up to the melting temperature of $2295 \pm 10^{\circ} \mathrm{C}$, and the stability region ranges from approximately 33 to $35 \mathrm{~mol} \% \mathrm{La}_{2} \mathrm{O}_{3}$ at $1500{ }^{\circ} \mathrm{C}$ (La/Zr atomic ratio 0.99 to 1.08) [13]. Due to the high fusion enthalpy of $\sim 350 \mathrm{~kJ} \mathrm{~mol}^{-1}$, solidification starts directly in the form of pyrochlore. However, considerable amounts of metastable fluorite phase are formed in the case of rapid solidification, which is typical of plasma spray conditions. This fluorite phase is transformed to pyrochlore at temperatures above $1000{ }^{\circ} \mathrm{C}$. This is not critical, as this transformation is not associated with a significant volume change. However, the processing of LZ by APS is still challenging, because lanthanum is prone to evaporation in the plasma plume, resulting in non-stoichiometric coatings. $\mathrm{La}_{2} \mathrm{O}_{3}$ shows considerably higher vapor pressure compared to $\mathrm{ZrO}_{2}$ [14]; this problem was already investigated by Cao et al. [12]. Later, the issue of the limited thermal stability of LZ again came up for discussion when new plasma torches, such as the three-cathode TriplexPro ${ }^{\mathrm{TM}}-210$ were applied, which are usually operated at elevated power levels. In [15], it is reported that severe lanthanum evaporation can occur such that considerable amounts of undesired zirconia are formed. As this is non-stabilized, it is subjected to phase transformations during TBC operation, associated with significant changes of the specific volume.

In this work, the development and testing of LZ/YSZ double layer TBC systems is described. Initially, suitable basic parameters (torch, plasma gas composition, and power) were tested with respect to coating stoichiometry. Then, microstructures were optimized by adjusting feed rate, spray distance, and selecting a more appropriate feedstock. The microstructures of powder particles and coatings were characterized by digital image analysis.

\section{Materials and Methods}

\subsection{Materials}

Three experimental powders were used in this study (Table 1). The particle size distributions of the feedstock powders were determined by laser diffraction (Horiba LA950, RETSCH Technology $\mathrm{GmbH}$, Haan, Germany).

For coating development, stainless steel substrates were generally used. If freestanding coatings were needed for particular characterization methods (see Section 2.2), coatings were sprayed on graphite substrates. For the thermal cycling tests, Inconel 738 LC substrates were used, having a 
diameter of $30 \mathrm{~mm}$, and were $3 \mathrm{~mm}$ thick. The rims of the substrates were rounded off in order to avoid edge effects. Plasma spraying under a low pressure (LPPS) with a F4 gun was used to deposit NiCoCrAlY bondcoats (Metco AMDRY 386), being $150 \mu \mathrm{m}$ thick. A commercially available 8YSZ powder (Metco 204 NS) was used for the first ceramic topcoat layer.

Table 1. Lanthanum zirconate (LZ) feedstock powder data.

\begin{tabular}{cccc}
\hline Feedstock & Manufacturing Route & $\boldsymbol{d}_{\mathbf{1 0}} / \boldsymbol{d}_{\mathbf{5 0}} / \boldsymbol{d}_{\mathbf{9 0}}(\boldsymbol{\mu \mathbf { m } )}$ & La/Zr Atomic Ratio \\
\hline $321 \mathrm{M}$ & Agglomerated and sintered & $17 / 37 / 74$ & 1.01 \\
322 I & Spray dried and sintered & $41 / 73 / 121$ & 1.03 \\
397 I & Spray dried and sintered & $33 / 63 / 116$ & 1.01 \\
\hline
\end{tabular}

\subsection{Methods}

The samples were coated by APS in a Multicoat facility (Oerlikon Metco, formerly Sulzer Metco, Wohlen, Switzerland) with a three-cathode TriplexPro ${ }^{\mathrm{TM}}-210$ torch mounted on a six-axis robot. For both the 8 YSZ and the LZ coatings, the $9 \mathrm{~mm}$ diameter nozzle was used with a $1.8 \mathrm{~mm}$ diameter feedstock injector. The standard plasma gas composition was 46 standard liters per minute (slpm) Ar and 4 slpm He. For 8 YSZ, the current was 420 A, while for LZ, it was varied between 275 A and 450 A, yielding plasma torch input powers between 22 and $42 \mathrm{~kW}$. To investigate the possible effect of hydrogen in the plasma gas, for LZ a composition of $40 \mathrm{slpm} \mathrm{Ar}$ and $10 \mathrm{slpm} \mathrm{H}_{2}$ was also applied at $275 \mathrm{~A}$, corresponding to a torch power of $32 \mathrm{~kW}$. Furthermore, a conventional one-cathode F4 gun was used for LZ, with a plasma gas mixture of $40 \mathrm{slpm}$ Ar and $10 \mathrm{slpm} \mathrm{H}_{2}$ at $250 \mathrm{~A}$ and 620 A yielding torch powers of $23 \mathrm{~kW}$ and $41 \mathrm{~kW}$, respectively; these were similar power levels as set for the TriplexPro ${ }^{\mathrm{TM}}-210$ torch. The spray distance was varied between 90 and $150 \mathrm{~mm}$.

The coatings sprayed on graphite substrates were subsequently stripped by grinding. Parts of the freestanding coatings were used for chemical analysis by optical emission spectroscopy with inductively coupled plasma (ICP-OES). The remaining samples were investigated by X-ray diffraction analysis (XRD) and then embedded into epoxy resin to prepare metallographic polished cross sections for microscopic investigation and elemental analysis. XRD was performed on a D4 ENDEAVOR diffractometer (Bruker AXS GmbH, Karlsruhe, Germany), and scanning electron microscope (SEM) investigation on an Ultra55 model (Carl Zeiss NTS GmbH, Oberkochen, Germany) combined with an energy-dispersive X-ray INCAEnergy355 spectrometer (EDS, Oxford Instruments Ltd., Abingdon, Oxfordshire, UK). Digital Image Analysis was performed by AnalySIS pro 5.0, Olympus Soft Imaging Solutions GmbH, Münster, Germany.

Details on the thermal cycling test setup can be found in [16]. The maximum surface temperature applied in this work was approximately $1400{ }^{\circ} \mathrm{C}$, while the bondcoat temperatures were kept at approximately $1070{ }^{\circ} \mathrm{C}$. Dwell times were $5 \mathrm{~min}$ for heating and $2 \mathrm{~min}$ for cooling.

\section{Results and Discussion}

\subsection{Plasma Spray Parameter Selection}

Initially, the effects of torch type, input power, and plasma gas composition on the coating stoichiometry were investigated. Table 2 gives the plasma parameters and the corresponding results of the chemical analyses. In all cases, the $321 \mathrm{M}$ powder was used with a feed rate of $8 \mathrm{~g} / \mathrm{min}$, and the spray distance was $90 \mathrm{~mm}$.

The major influence on the coating stoichiometry is exerted by the torch power. At higher levels (450 A with TriplexPro ${ }^{\mathrm{TM}}-210$ and 620 A with F4), severe La depletion was observed in each case. The reason is the significantly higher vapor pressure of lanthania compared to zirconia. If the TriplexPro ${ }^{\mathrm{TM}}-210$ is operated with hydrogen as secondary plasma gas, the stoichiometry is also strongly affected. This is probably due to the high thermal conductivity of hydrogen in combination with the high torch efficiency. Moreover, it is noteworthy that the conventional one-cathode F4 gun still induces a slight La depletion, even in the case of low input power, while the three-cathode TriplexPro ${ }^{\mathrm{TM}}-210$ 
operated at the same power does not. It is suggested that this is achieved by the more stable operation with lower arc fluctuations of the latter.

Table 2. Plasma parameters and corresponding results of the chemical analyses of the coating stoichiometry (spray distance $90 \mathrm{~mm}$, powder $321 \mathrm{M}$, feed rate $8 \mathrm{~g} / \mathrm{min}$ ); slpm: standard liters per minute.

\begin{tabular}{ccccc}
\hline Spray Run & Torch & Current (A)/Power (kW) & $\begin{array}{c}\text { Plasma Gas } \\
\text { Ar/He/ } \mathbf{H}_{\mathbf{2}} \text { (slpm) }\end{array}$ & La/Zr Atomic Ratio \\
\hline 130 & TriplexPro $^{\mathrm{TM}}-210$ & $275 / 22$ & $46 / 4 /-$ & 1.00 \\
129 & TriplexPro $^{\mathrm{TM}}-210$ & $450 / 42$ & $46 / 4 /-$ & 0.89 \\
143 & TriplexPro $^{\mathrm{TM}}-210$ & $275 / 32$ & $40 /-/ 10$ & 0.77 \\
142 & $\mathrm{~F} 4$ & $250 / 23$ & $40 /-/ 10$ & 0.95 \\
141 & $\mathrm{~F} 4$ & $620 / 41$ & $40 /-/ 10$ & 0.87 \\
\hline
\end{tabular}

It is shown in [15] that the stoichiometry of LZ coatings is well-reflected by the lattice parameter. In the as-sprayed state, LZ is obtained as a metastable fluorite with space group 225 (Fm-3m, cubic). La depletion leads to a decrease of the lattice parameter, which is well-correlated to the $\mathrm{La} / \mathrm{Zr}$ atomic ratio determined by chemical analysis. In Figure 1, this is shown for the as-sprayed samples given in Table 2, as well as for the applied feedstock material $321 \mathrm{M}$.

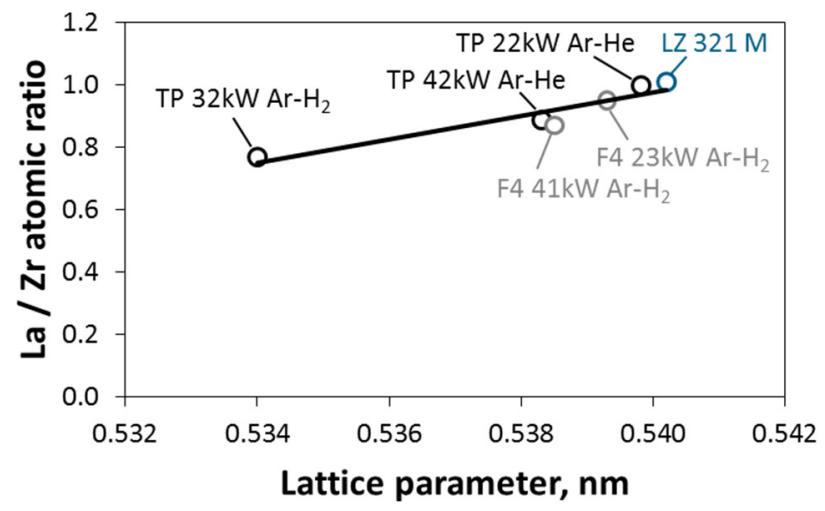

Figure 1. Correlation of La depletion and LZ Fluorite lattice parameter for different torch types (TP: TriplexPro ${ }^{\mathrm{TM}}-210$, F4 gun), input power levels, and plasma gas compositions; the data of powder feedstock $321 \mathrm{M}$ is given as a reference.

Figure 2 shows the EDS elemental mapping of a coating sprayed with TriplexPro ${ }^{\mathrm{TM}}-210$ at high power $(42 \mathrm{~kW})$ and with Ar-He plasma gas mixture. As already indicated by the different grey tones in the back-scattered electron image, the EDS results show a severe La depletion running along the splat structures. It is assumed that the La evaporation occurs mainly in-flight from the particle near-surface regions.

The results indicate that the processing of LZ by APS must be done at limited power in order to avoid inhomogeneous evaporation. Comparing the deposition efficiencies for the use of the different torches, power levels, and plasma gas compositions (Table 3), the highest values were found at the higher input power levels (Figure 3). However, the differences to the samples sprayed at low power are relatively small, such that only minor losses must be accepted for the sake of desired coating stoichiometry. Only the deposition efficiency for TriplexPro ${ }^{\mathrm{TM}}-210$ with argon-hydrogen parameter was poor (run 143, not plotted).

Furthermore, porosities were determined by digital image analyses. The images were binarized setting a user-defined greyscale threshold. Then, the areas related to the pores and voids were measured. The porosities reveal that the coatings sprayed at high power are too dense to be applied as TBCs. Thus, spraying at low power level helps also to increase porosities towards the requirements 
on TBCs. The low powder feed rate can explain the fact that similar deposition efficiencies were observed when using the TriplexPro ${ }^{\mathrm{TM}}-210$ and the F4. At higher rates, considerable differences should be expected. Hence, the use of the F4 torch was not continued.

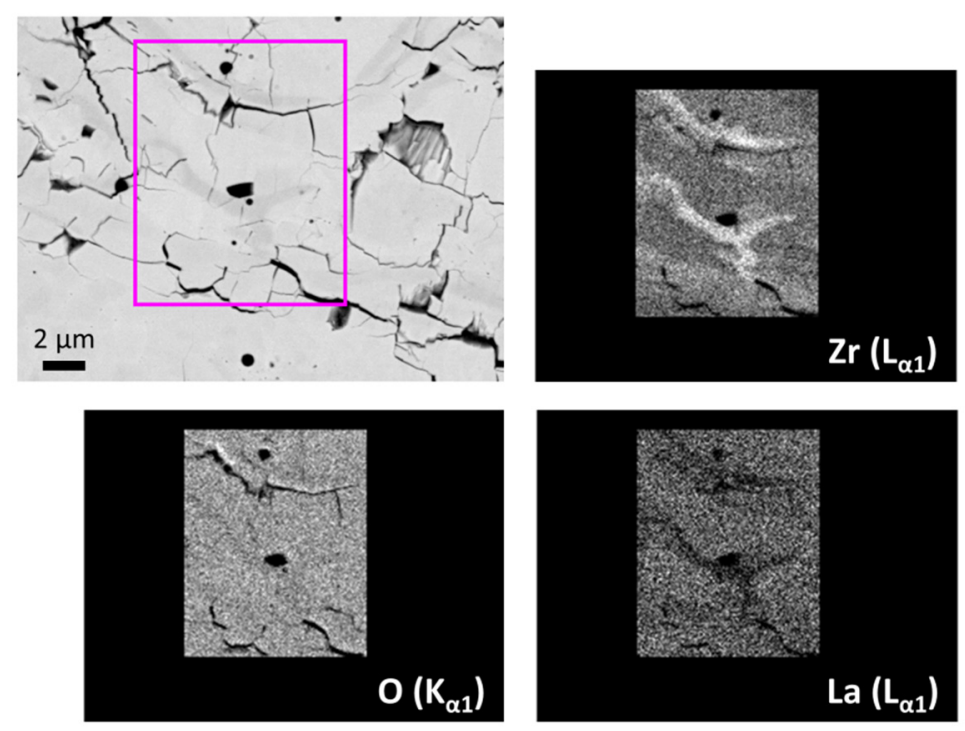

Figure 2. Back-scattered electron image and energy-dispersive X-ray spectrometry (EDS) elemental mappings of a coating sprayed with TriplexPro ${ }^{\mathrm{TM}}-210$ at high power $(42 \mathrm{~kW})$ and with Ar-He plasma gas mixture porosities (powder $321 \mathrm{M}$, spray distance $90 \mathrm{~mm}$ ).

Table 3. Effect of plasma parameters on deposition efficiencies and coating porosities (spray distance $90 \mathrm{~mm}$, powder $321 \mathrm{M}$, feed rate $8 \mathrm{~g} / \mathrm{min}$ ); porosities averaged from two images.

\begin{tabular}{|c|c|c|c|c|c|}
\hline Spray Run & Torch & $\begin{array}{c}\text { Current } \\
\text { (A)/Power (kW) }\end{array}$ & $\begin{array}{c}\text { Plasma Gas } \\
\mathrm{Ar} / \mathrm{He} / \mathrm{H}_{2}\left(\operatorname{slpm}^{1}\right)\end{array}$ & $\begin{array}{c}\text { Deposition } \\
\text { Efficiency (\%) }\end{array}$ & Porosity (\%) \\
\hline 130 & TriplexPro $^{\mathrm{TM}}-210$ & $275 / 22$ & $46 / 4 /-$ & 55 & $14.5 \pm 0.2$ \\
\hline 129 & TriplexPro $^{\mathrm{TM}}-210$ & $450 / 42$ & $4 / 4 /-$ & 62 & $8.6 \pm 0.3$ \\
\hline 143 & TriplexPro $^{\mathrm{TM}}-210$ & $275 / 32$ & $40 /-/ 10$ & 47 & not measured \\
\hline 142 & $\mathrm{~F} 4$ & $250 / 23$ & $40 /-/ 10$ & 59 & $13.2 \pm 0.7$ \\
\hline 141 & F4 & $620 / 41$ & $10 /-/ 10$ & 60 & $8.3 \pm 0.4$ \\
\hline
\end{tabular}

${ }^{1}$ standard liters per minute.

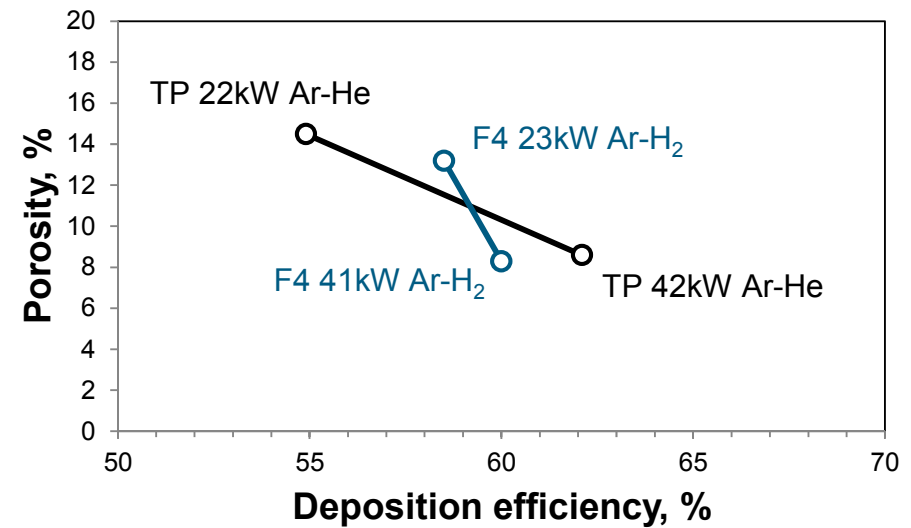

Figure 3. Deposition efficiencies and coating porosities for different plasma parameters (spray distance $90 \mathrm{~mm}$, powder $321 \mathrm{M}$, feed rate $8 \mathrm{~g} / \mathrm{min}$ ); porosities averaged from two images.

Because the porosities at low power $(22 \mathrm{~kW})$ still appeared not to be entirely sufficient, the spray distance and the powder feed rate were increased (Table 4 ). Figure 4 gives the corresponding deposition 
efficiencies and the porosities determined by image analysis for the use of this torch with Ar-He plasma gas mixture and powder $321 \mathrm{M}$. While there are obvious effects of the spray distance and the feed rate on the deposition efficiency, the effect on the porosity is less pronounced.

Table 4. Effect of spray distances and powder feed rates on deposition efficiencies and coating porosities (TriplexPro ${ }^{\mathrm{TM}}-210$ at low power with Ar-He plasma gas mixture $(22 \mathrm{~kW})$, powder $\left.321 \mathrm{M}\right)$; porosities averaged from three images.

\begin{tabular}{ccccc}
\hline Spray Run & $\begin{array}{c}\text { Spray Distance } \\
(\mathbf{m m})\end{array}$ & $\begin{array}{c}\text { Powder Feed Rate } \\
\text { (g/min) }\end{array}$ & $\begin{array}{c}\text { Deposition } \\
\text { Efficiency (\%) }\end{array}$ & Porosity (\%) \\
\hline 255 & 90 & 8 & 56 & $14.6 \pm 0.5$ \\
256 & 90 & 32 & 55 & $14.2 \pm 0.4$ \\
257 & 90 & 80 & 47 & $12.8 \pm 0.2$ \\
258 & 150 & 8 & 40 & $17.3 \pm 1.0$ \\
266 & 150 & 32 & 30 & $15.5 \pm 1.1$ \\
267 & 150 & 80 & 27 & $14.2 \pm 1.4$ \\
\hline
\end{tabular}

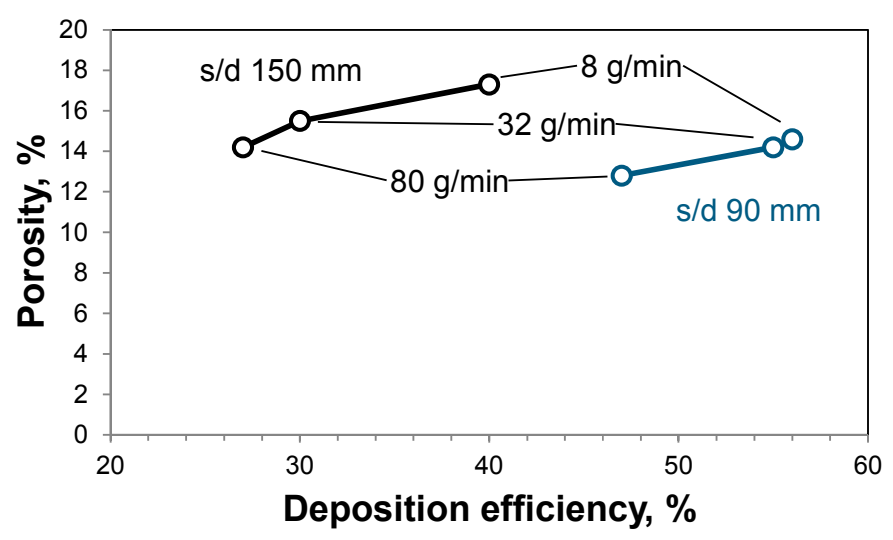

Figure 4. Deposition efficiencies and coating porosities for different spray distances and powder feed rates (TriplexPro ${ }^{\mathrm{TM}}-210$ at low power with Ar-He plasma gas mixture, powder $321 \mathrm{M}$ ); porosities averaged from three images.

With the TriplexPro ${ }^{\mathrm{TM}}-210$, different plasma gas mixtures were also tried to obtain colder conditions, and thus to increase the porosity. Using only $50 \mathrm{slpm} \mathrm{Ar}$ as well as $70 \mathrm{slpm} \mathrm{Ar}+6 \mathrm{slpm} \mathrm{He}$ at $90 \mathrm{~mm}$ and $150 \mathrm{~mm}$ spray distance led to coarse non-molten deposits. Furthermore, the deposition efficiencies were poor, so these results are not presented here in detail; this direction was not followed up.

Based on the overall results obtained so far, the following spray parameters were selected for the first burner rig test samples: TriplexPro ${ }^{\mathrm{TM}}-210$ with Ar-He plasma gas mixture, $275 \mathrm{~A}(22 \mathrm{~kW})$, powder feed rate $8 \mathrm{~g} / \mathrm{min}$, powder $321 \mathrm{M}$. Two samples sprayed at $90 \mathrm{~mm}$ distance survived only seven and three cycles, respectively, and another two samples sprayed at $150 \mathrm{~mm}$ reached only 14 and 16 cycles, respectively. Figure 5 shows one cycled example. The coatings failed due to the early formation of cracks in the ceramic layers. Obviously, the compliance of the system is poor, qualified by the characteristics of the microstructure. It is obvious that the overall porosity is still too low. As the microstructure is obviously dominated by inter- and intra-splat cracks, the lack of finely-distributed pores of a more globular shape is supposed to be a further reason for the insufficient strain tolerance. In the following, the approach to improving this situation was to select different feedstock powders. 


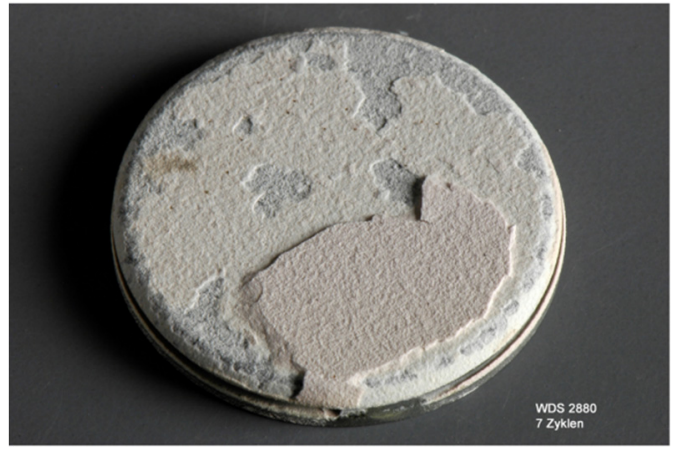

(a)

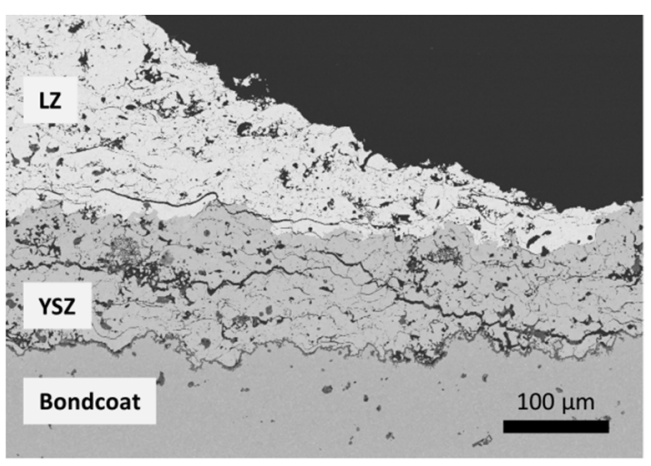

(b)

Figure 5. (a) Double-layer sample, LZ sprayed with TriplexPro ${ }^{\mathrm{TM}}-210$ at low power $(22 \mathrm{~kW})$ and with Ar-He plasma gas mixture (spray distance $90 \mathrm{~mm}$, powder $321 \mathrm{M}$, feed rate $8 \mathrm{~g} / \mathrm{min}$ ) after seven thermal cycles; (b) back-scattered electron image of the cross-section.

\subsection{Powder Feedstock Selection}

The alternative powders 322 I and 397 I had almost stoichiometric compositions comparable to the $321 \mathrm{M}$ used so far. However, the particle size distribution was shifted considerably to larger diameters (see Table 1). Furthermore, the internal microstructure of the particles was finer, as can be seen from typical cross-sections of powder particles in Figure 6 . The diameters $d_{P}$ of these primary particles (i.e., diameters of equivalent circles equal in area) were evaluated by digital image analyses. The corresponding volumetric distributions are given in Figure 7, where each curve was averaged from three SEM images. It is evident that the $321 \mathrm{M}$ powder contained significantly larger primary particles compared to $322 \mathrm{I}$ and $397 \mathrm{I}$.

The large particle diameters and the small primary particle size have a significant effect on the coating microstructures. Figure 8 gives three typical examples sprayed with the three investigated powders using the TriplexPro ${ }^{\mathrm{TM}}-210$ torch at low power $(22 \mathrm{~kW})$ and with the Ar-He plasma gas mixture. Besides the coarse more-or-less globular porosity fractions, the fine fractions appear differently. For the $321 \mathrm{M}$ feedstock, it is mainly a network of long and narrow inter-splat and intra-splat cracks, while for the 322 I and the 397 I powder, the fine porosity also consists of many accumulations of globular pores. It is suggested that the melting grade of the $321 \mathrm{M}$ feedstock was higher due to the smaller granule size, while in case of the 322 I and the 397 I powder, partly unmolten fractions were embedded in the coatings. In these domains, the fine primary particle structure was partially preserved.

The coarse porosity fraction was determined by the application of morphological dilatation and erosion filters, and then subtracted from the total porosity [17] to obtain the fine fraction. The percentages were averaged from three SEM images for each feedstock. Considering the fine porosities, it should be kept in mind that the fractions are volumetric, so small differences imply large variances in the numbers of voids.

Using the 322 I and 397 I powders, two burner rig test samples were each sprayed with the same parameters. The corresponding as-sprayed microstructures can be seen by looking at the examples in Figure 8. In Figure 9, the cycles to failure are displayed; the results for the test samples from powder $321 \mathrm{M}$ (mentioned above) are given as a reference. The lifetimes were 1398 and 1750 cycles for the 322 I powder and 1318 and 1423 cycles for 397 I, respectively. These results correspond to what was already reached some time ago [8] using the older Triplex I torch with low power capability $(21 \mathrm{~kW})$. Furthermore, the results correlate with the porosity characteristics. With the $322 \mathrm{I}$ feedstock exhibiting the largest powder grains and the smallest primary particles, the highest coarse and fine porosities were obtained. It is likely that the fine porosity content was still larger than resolved by the SEM images. The fine pore structures contained much more globular voids beside the crack network. 
The importance of this kind of fine porosity for the properties and lifetimes of TBCs was already reported for $\mathrm{Gd}_{2} \mathrm{Zr}_{2} \mathrm{O}_{7} / \mathrm{YSZ}$ double-layer systems in [18].

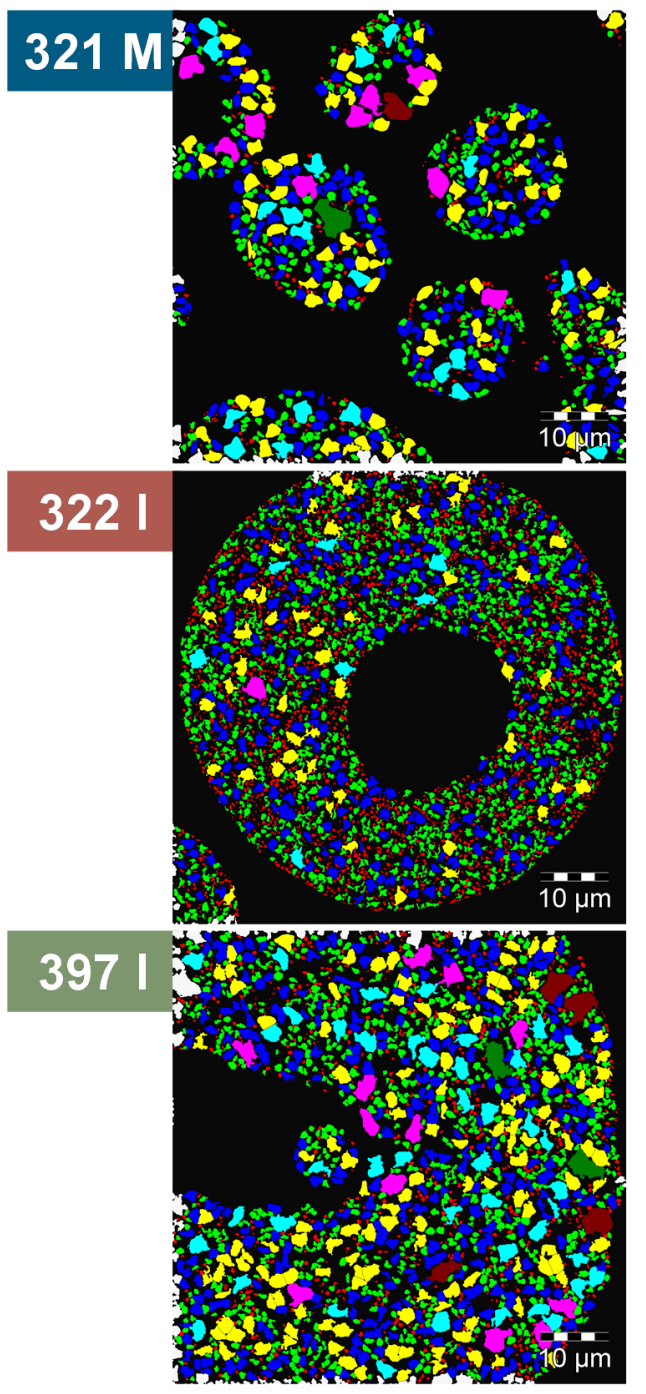

Figure 6. Powder cross-sections (binarized back-scattered electron images, the primary particle size is expressed by the pseudo-colors) of the three investigated LZ powders.

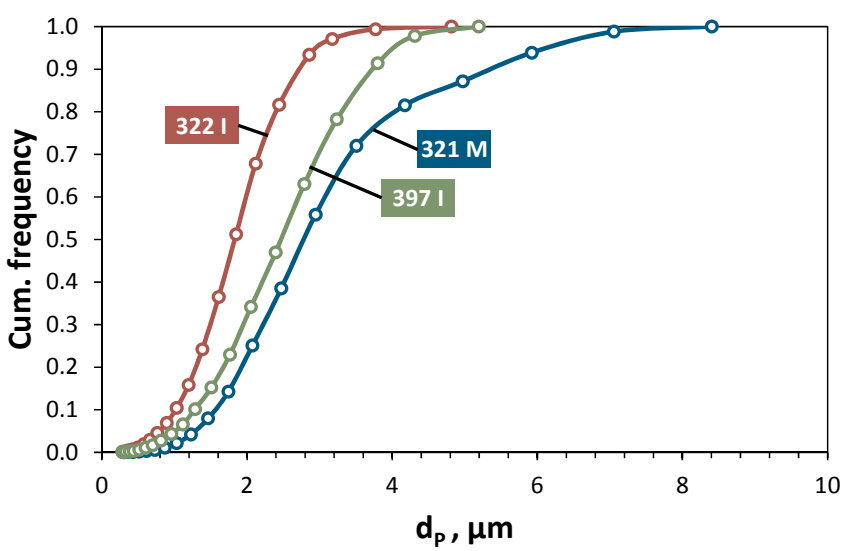

Figure 7. Volumetric cumulative distribution functions of the primary particle equivalent diameters $d_{P}$ for the three investigated LZ powders; curves are averaged from three SEM images. 

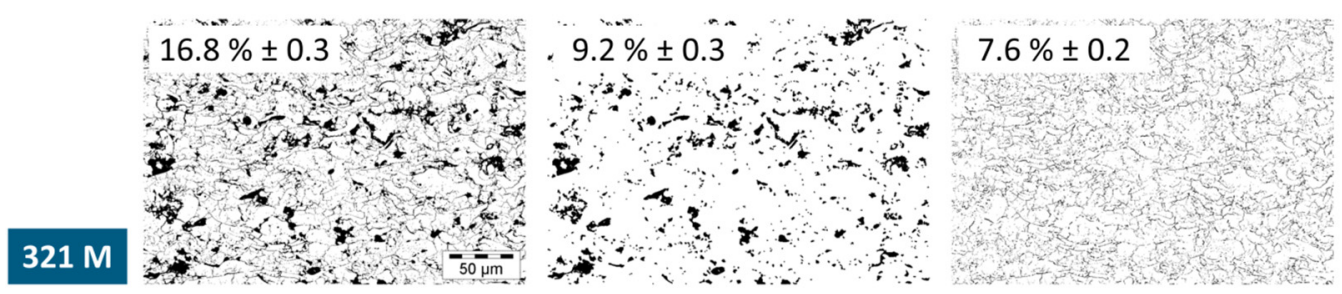

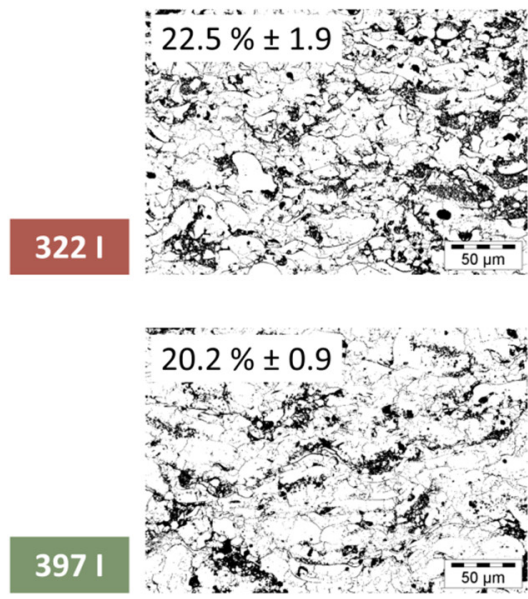

(a)
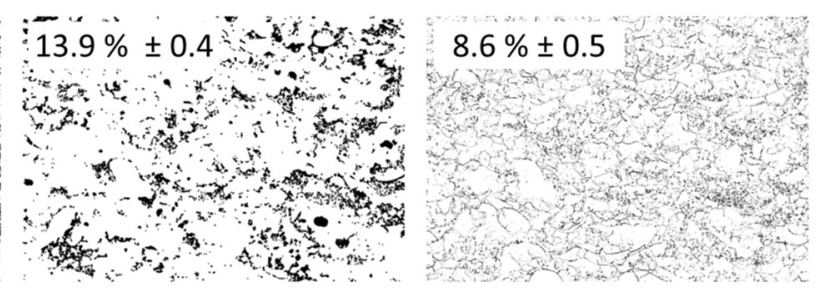

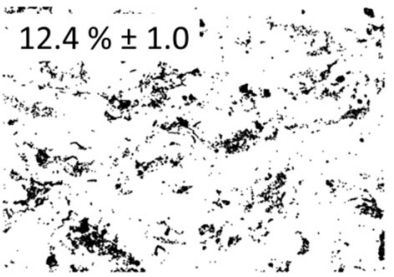

(b)

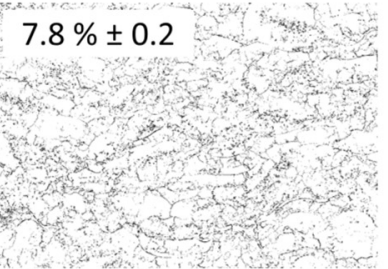

(c)

Figure 8. Typical examples of porosities (a) total porosity; (b)coarse porosity fraction; (c) fine porosity fraction) for the three investigated LZ powders processed by TriplexPro ${ }^{\mathrm{TM}}-210$ torch at low power $(22 \mathrm{~kW})$ and with Ar-He plasma gas mixture (binarized back-scattered electron images); porosity volume percentages were averaged from three images.

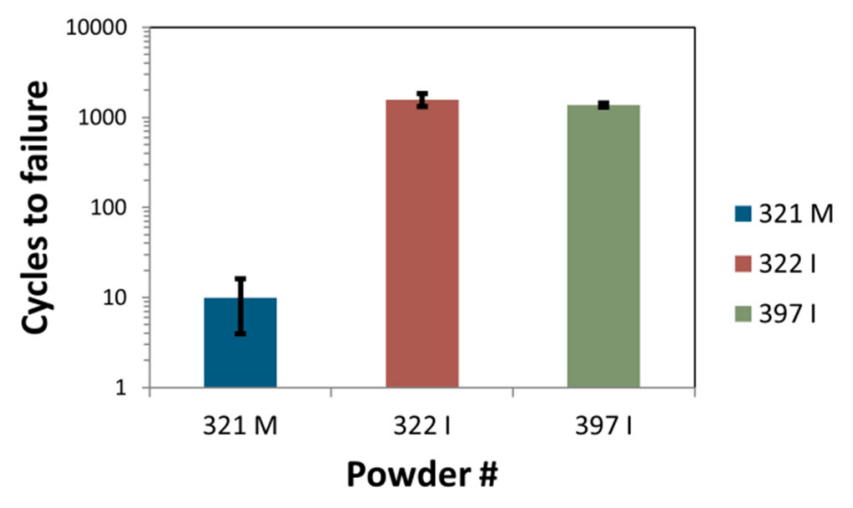

Figure 9. Cycles to failure of burner rig test samples sprayed with LZ powders $321 \mathrm{M}, 322 \mathrm{I}$, and 397 I processed by TriplexPro ${ }^{\mathrm{TM}}-210$ torch at low power $(22 \mathrm{~kW})$ and with Ar-He plasma gas mixture; note the logarithmic scale.

The failure of the samples was induced by the growth of the TGO at the interface of bondcoat and ceramic top coat (Figure 10).The ceramic topcoat was obviously sufficiently strain tolerant to accommodate the thermal stresses due to the thermal mismatch with the metallic substrate and the temperature gradient in the burner rig. 


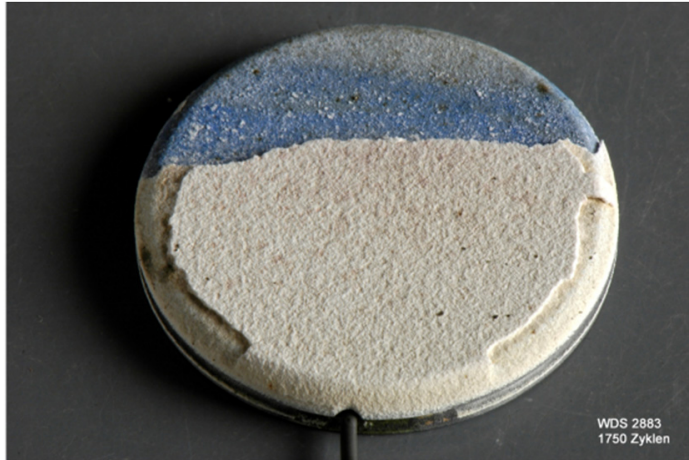

(a)

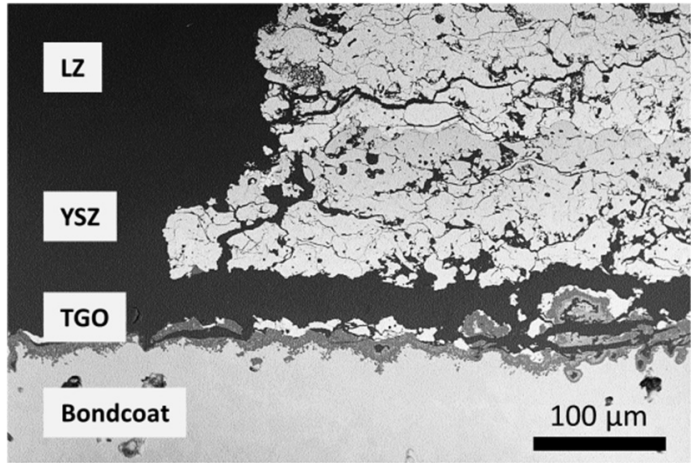

(b)

Figure 10. (a) Double-layer sample, LZ sprayed with TriplexPro ${ }^{\mathrm{TM}}-210$ at low power $(22 \mathrm{~kW})$ and with Ar-He plasma gas mixture (spray distance $150 \mathrm{~mm}$, powder $322 \mathrm{I}$, after 1750 thermal cycles; (b) back-scattered electron image of the cross-section.

It must be noted that these porous, compliant structures could be more prone to erosion-related damage. In such cases, dense vertically cracked coatings (DVCs) can offer improved resistance. However, since DVC deposition typically involves a higher degree of plasma enthalpy and heat flux, the preferential La depletion might again become an issue - this is still to be investigated.

\section{Conclusions}

In this work, spray parameters for LZ as a TBC top layer were optimized in a stepwise manner. Initially, plasma parameters were identified to avoid lanthanum depletion. Further, spray parameters were varied with respect to appropriate porosity and deposition efficiency. Sufficient strain-tolerant coatings could be obtained at last by optimizing the feedstock structure and morphology.

The following conclusions can be drawn:

- $\quad$ LZ for TBC systems must be processed by APS at low power to avoid inhomogeneous feedstock evaporation and non-stoichiometric coating compositions. Nevertheless, reasonable deposition efficiencies can be obtained. Ar-He plasma gas mixtures are preferable instead of $\mathrm{Ar}-\mathrm{H}_{2}$.

- The microstructures determine the mechanical properties considerably. To achieve sufficient strain tolerance, the total porosity should be at least $\sim 20 \%$. Furthermore, the fine fractions should contain adequate amounts of globular pores beside the intra- and inter-splat crack network. This can be investigated advantageously by digital image analysis of coating cross-sections.

- Appropriate fine porosity fractions can be obtained at low plasma power and from large feedstock particles with small primary particles in the range of some very few microns. Digital image analyses of particle cross-sections are valuable means to study the feedstock microstructure.

Author Contributions: G.M., L.D., and R.V. conceived and designed the experiments; L.D. performed the experiments; G.M. and L.D. analyzed the data; G.M. wrote the paper.

Conflicts of Interest: The authors declare no conflict of interest.

\section{References}

1. Mauer, G.; Vaßen, R. Technology Vision: Current Developments and Challenges in Thermal Barrier Coatings. Surf. Eng. 2011, 27, 477-479.

2. Clarke, D.R.; Oechsner, M.; Padture, N.P. Thermal-barrier coatings for more efficient gas-turbine engines. MRS Bull. 2012, 37, 891-898. [CrossRef]

3. Schulz, U. Phase Transformation in EB-PVD Yttria Partially Stabilized Zirconia Thermal Barrier Coatings during Annealing. J. Am. Ceram. Soc. 2000, 83, 904-910. [CrossRef] 
4. Cipitria, A.; Golosnoy, I.O.; Clyne, T.W. A sintering model for plasma-sprayed zirconia TBCs. Part I: Free-standing coatings. Acta Mater. 2009, 57, 980-992. [CrossRef]

5. Vaßen, R.; Cao, X.Q.; Tietz, F.; Basu, D.; Stöver, D. Zirconates as New Materials for Thermal Barrier Coatings. J. Am. Ceram. Soc. 2000, 83, 2023-2028. [CrossRef]

6. Clarke, D.R.; Phillpot, S.R. Thermal barrier coating materials. Mater. Today 2005, 8, 22-29. [CrossRef]

7. Cao, X.Q.; Vaßen, R.; Stöver, D. Ceramic materials for thermal barrier coatings. J. Eur. Ceram. Soc. 2004, 24, 1-10. [CrossRef]

8. Vaßen, R.; Traeger, F.; Stöver, D. New Thermal Barrier Coatings Based on Pyrochlore/YSZ Double-Layer Systems. Int. J. Appl. Ceram. Technol. 2004, 1, 351-361. [CrossRef]

9. Cao, X.Q.; Vaßen, R.; Tietz, F.; Stöver, D. New double-ceramic-layer thermal barrier coatings based on zirconia-rare earth composite oxides. J. Eur. Ceram. Soc. 2006, 26, 247-251. [CrossRef]

10. Viswanathan, V.; Dwivedi, G.; Sampath, S. Engineered Multilayer Thermal Barrier Coatings for Enhanced Durability and Functional Performance. J. Am. Ceram. Soc. 2014, 97, 2770-2778. [CrossRef]

11. Viswanathan, V.; Dwivedi, G.; Sampath, S. Multilayer, Multimaterial Thermal Barrier Coating Systems: Design, Synthesis, and Performance Assessment. J. Am. Ceram. Soc. 2015, 98, 1769-1777. [CrossRef]

12. Cao, X.Q.; Vaßen, R.; Jungen, W.; Schwartz, S.; Tietz, F.; Stöver, D. Thermal Stability of Lanthanum Zirconate Plasma-Sprayed Coating. J. Am. Ceram. Soc. 2001, 84, 2086-2090. [CrossRef]

13. Radha, A.V.; Ushakov, S.V.; Navrotsky, A. Thermochemistry of lanthanum zirconate pyrochlore. J. Mater. Res. 2009, 24, 3350-3357. [CrossRef]

14. Margrave, J.L. The Characterization of High Temperature Vapors; Wiley: New York, NY, USA, 1967.

15. Mauer, G.; Sebold, D.; Vaßen, R.; Stöver, D. Improving Atmospheric Plasma Spraying of Zirconate Thermal Barrier Coatings Based on Particle Diagnostics. J. Therm. Spray Technol. 2012, 21, 363-371. [CrossRef]

16. Traeger, F.; Vaßen, R.; Rauwald, K.-H.; Stöver, D. Thermal Cycling Setup for Testing Thermal Barrier Coatings. Adv. Eng. Mater. 2003, 5, 429-432. [CrossRef]

17. Sobhanverdi, R.; Akbarin, A. Porosity and microstructural features of plasma sprayed Yttria stabilized Zirconia thermal barrier coatings. Ceram. Int. 2015, 41, 14517-14528. [CrossRef]

18. Bakan, E.; Mack, D.E.; Mauer, G.; Mücke, R.; Vaßen, R. Porosity-Property Relationships of Plasma-Sprayed $\mathrm{Gd}_{2} \mathrm{Zr}_{2} \mathrm{O}_{7} / \mathrm{YSZ}$ Thermal Barrier Coatings. J. Am. Ceram. Soc. 2015, 98, 2647-2654. [CrossRef]

(C) 2016 by the authors; licensee MDPI, Basel, Switzerland. This article is an open access article distributed under the terms and conditions of the Creative Commons Attribution (CC-BY) license (http://creativecommons.org/licenses/by/4.0/). 